\title{
Metaphors of disease in the Russian press
}

\section{[Метафоры болезни в российской прессе]}

\author{
Eduard Budaev
}

\section{DOI: 10.18355/XL.2017.10.02.03}

\begin{abstract}
Аннотация
Статья посвящена исследованию динамики метафор болезни в российской прессе 2000-2010 гг. Контент-анализ корпуса из 86000 текстов позволил обнаружить три периода в функционировании морбиальной метафорики в рассматриваемый период. В 2000-2006 гг. частотность метафор болезни планомерно снижалась, что коррелирует с представлениями российских граждан о повышении уровня жизни и экономической стабильности. Накануне мирового экономического кризиса в 2007 г. отмечается незначительный рост частотности метафор болезни, который резко усиливается в острую фазу экономического кризиса 2008-2009 гг. В 2010 г. снова отмечается небольшое снижение частотности метафор болезни, что коррелирует с представлениями граждан России о стабилизации социально-экономической ситуации в этот период.

Ключевые слова: метафора, концептуальная метафора, российская пресса, диахрония, дискурс СМИ
\end{abstract}

\section{Введение}

Исследование хронологической динамики политической метафоры одно из интенсивно развивающихся направлений науки, находящееся на пересечении диахронического языкознания, когнитивной лингвистики и политологии. Стабильность метафорической картины мира проявляется в том, что политическая метафорика имеет устойчивое ядро, которое сохраняется с глубокой древности. Согласно этой точке зрения, и в Древней Греции, и в средневековой Европе, и в современном мире политические метафоры во многом похожи, поскольку отражают устойчивые детерминанты человеческого сознания или архетипы коллективного бессознательного. Темпоральная стабильность дополняется значительным параллелизмом метафорической картины мира в различных регионах земного шара. Применительно к политическим метафорам эта точка зрения была последовательно сформулирована Майклом Осборном и его единомышленниками в теории архетипичных метафор. Эта концепция опиралась на методологию бихевиоризма, хотя в принципе подобные выводы могут находить методологическое основание в разных теориях (структурализм В. Я. Проппа, историческая поэтика А. Н. Веселовского, аналитическая психология К. Г. Юнга, экспериенциальный реализм и теория «телесного разума» Дж. Лакоффа и М. Джонсона).

Действительно, схожие метафоры фиксируются исследователями в разных культурах и в разные времена. Например, метафоры болезни регулярно используются для представления врага в разных странах и в разные эпохи, хотя сфера-мишень для метафор меняется в зависимости от политической конъюнктуры, адресата и адресанта дискурса. Если во Франции XVI в. 
сторонники Бурбонов видели причину болезни страны в католицизме, то французские католики считали источником недуга распространение протестантской ереси. Показательно, что и те, и другие подразумевали под «лечением» уничтожение идейных противников, чем антагонисты и занимались в затяжных гугенотских войнах. Подобные метафоры обнаруживаются много лет спустя в риторике А. Гитлера и его единомышленников, видевших причины болезней Германии в заговоре «паразитов-евреев» (Musolff 2006). Не менее востребованной оказалась метафорика из сферы-источника «Болезнь» в политических дискурсах второй половины XX в. (Elwood, 1995; Kelly-Holmes, O'Regan, 2004; Milliken, 1996; Musolff, 2004, 2016; Nasalski, 2004; Oberlechner, Mayer-Schönberger, 2002; Zbierska-Sawala, 2004).

По мере накопления конкретных наблюдений становилось очевидным, что политическая метафорика обладает значительной диахронической вариативностью. Социально-политическое развитие общества вместе с развитием производительных сил закономерно ведет к развитию метафорических систем. Для нашего исследования особую значимость имеет вопрос об исторической динамике российских (советских) политических метафор. Уже в первых отечественных публикациях по этой проблеме было отмечено, что в сталинскую эпоху доминировали метафоры войны и механизма, во времена Л. И. Брежнева максимально активизировались метафоры родства, а доместические и строительные метафоры - отличительный признак эпохи перестройки (Baranov, 2014). Соответственно метафоры из сфер-источников «Театр», «Криминальный мир», «Монархия» - яркая примета периода президентства Бориса Ельцина (Chudinov, 2001).

Использование метафор болезни характеризуется сильным эмотивным потенциалом. Людям внушается мысль о том, что государство в целом и его отдельные составляющие нужно срочно лечить сильнодействующими лекарствами, поскольку отдельные органы организма уже омертвели и потеря времени грозит самыми печальными последствиями (полная инвалидность, смерть, эпидемия). Выписываемые властями рецепты могут только повредить больному, поскольку политические лекари получили неправильное образование и, возможно, подкуплены ожидающими наследства соседями. Соответствующие рассматриваемой концептуальной метафоре образы объединяются концептуальными векторами агрессивности и тревожности, в них отражаются безысходность, дурные предчувствия и вместе с тем, душевная боль за состояние родной страны, ощущение собственного бессилия. Еще один сильный концептуальный вектор для рассматриваемой модели - отклонение от естественного порядка вещей, представления о неправильности и недопустимости существующего положения.

\section{Методология исследования}

В настоящем исследовании ставится задача проследить динамику изменения метафор болезни в современных российских СМИ за период 20002010 гг. Исследуемый материал ограничивается метафорикой из сферыисточника «Болезнь», потому что именно эта сфера-источник метафорической экспансии относится к наиболее «чувствительным» к экстралингвистическим условиям сферам (Chudinov, 2001; De Landtsheer, 1991; De Leonardis, 2008; Moreno Lara, 2004; Musolff, 2004).

Для решения поставленной этой задачи используется методика контентанализа, занимающая значимое место в современных исследованиях СМИ и 
политической коммуникации. Контент-анализ по целому ряду признаков противопоставлен дискурс-анализу:

$$
\text { - дискурс-анализ - квалитативный метод, контент-анализ - }
$$

квантитативный метод;

- дискурс-анализ основывается на постулате социального конструктивизма (дискурс конструирует политическую реальность) - контентанализ онтологически ориентирован на реализм, т. е. на изучение текстов как одного из проявлений политической реальности, а не факторов ее генезиса;

- в дискурс-анализе семантика текстов считается вариативной и эксплицируется посредством интерпретации - контент-анализ ориентирован на статическое представление семантики текстов, верифицируемое с помощью математических методов;

- дискурс-анализ включает в себя изучение условий порождения и функционирования текстов (экстралингвистический контекст) - контент-анализ, ориентированный на статистические закономерности, не предусматривает обязательного изучения контекста.

Ярким примером применения контент-анализа к анализу метафорики является методика метафорических индексов, разработанная Х. Де Ландтсхеер и ее коллегами в рамках комбинаторной теории кризисной коммуникации (СССtheory). X. Де Ландтсхеер доказала на примере анализа голландского политического дискурса, что существует зависимость между частотностью метафор и общественными кризисами (De Landtsheer, 1991). В очередном исследовании X. Де Ландтсхеер и Д. Фертессен рассмотрели стилистическую динамику языка политики (Vertessen, De Landtsheer, 2008). Сопоставляя метафорику бельгийского предвыборного дискурса с метафорикой дискурса в периоды между выборами, авторы обнаружили, что показатель метафорического индекса увеличивается в предвыборный период. Выявленная зависимость проявлялась применительно к «желтой» и «серьезной» прессе, а также не выявляет больших различий при анализе коммерческих и государственных СМИ. Эти результаты позволили авторам говорить об особенном, характеризующемся повышенной метафоричностью предвыборном стиле политического языка

Вместе с тем между контент-анализом и дискурс-анализом нет непроходимых границ. В современной лингвистике для обозначения подхода, который совмещает эвристики дискурс-анализа и корпусной лингвистики, используется специальный термин corpus-assisted discourse studies (CADS, дискурс-анализ с помощью корпусного анализа). Методика CADS в общем виде состоит из двух частей: выборка материала из корпуса и квалитативный анализ материалов выборки. Такой подход, ослабивший противопоставление контентанализа и дискурс-анализа, получил широкое применение в современной политической лингвистике (Bevitori, 2015; Clark, 2008; Murphy, 2009; Partington, 2010; Riccio, 2009, Lombardo, 2007; Vessey, 2016). Применение контент-анализа оказывает значимую помощь для анализа дискурсивного, что все чаще находит понимание у современных лингвистов.

Для нашего исследования квантитативный ракурс анализа связан с рядом методологических аспектов, требующих отдельного внимания. При определении параметра вычисления можно учитывать количество метафор в определенном сегменте диахронического отрезка в абсолютном исчислении или учитывать количество метафор из определенной сферы-источника в относительном исчислении, т.е. в процентном показателе от общего числа 
метафор. При анализе метафорики из определенной сферы-источника долевой подсчет слабо пригоден. Вместе с тем использование абсолютного показателя применимо с некоторыми оговорками.

Необходимо принимать во внимание, что абсолютный количественный показатель не отражает динамику метафорики, если распределение анализируемого материала не сбалансировано по сегментам по критерию количества слов или текстов. При сбалансированном подходе отношение устанавливается не к метафорам других сфер-источников, а к количеству других единиц (слов, предложений, текстов). Отметим, что от сегмента к сегменту варьируется не только количество метафор определенной сферыисточника метафорической экспансии, но и общее количество метафор. Следовательно, увеличение количества метафор определенной сферыисточника может быть связано с общим увеличением метафоричности. Отсюда может последовать ошибочный вывод о том, что рассмотренное обстоятельство способно снизить уровень достоверности подсчетов по абсолютному показателю. Важно учитывать, что общее увеличение метафоричности происходит не за счет пропорционального увеличения всех сфер-источников метафорической экспансии, а только за счет некоторых из них, прагматический потенциал и концептуальные векторы которых востребованы на определенном этапе политической жизни общества. Следовательно, увеличение метафоричности политического дискурса, произошедшее за счет сферисточников, не принимаемых во внимание, не отразится на анализируемых показателях, а увеличение метафоричности, связанное с ростом метафор из рассматриваемой понятийной области, разумеется, будет зафиксировано в абсолютном показателе количества метафор.

Для контент-анализа в нашем исследовании использовался корпус, включающий в себя статьи из 314 общероссийских и региональных периодических изданий за 10 лет общим числом 84000 текстов. Включение в корпус региональной прессы обусловлено целым рядом причин. Так как общероссийские издания характеризуются высокими тиражами, они потенциально способны оказывать прагматическое воздействие на большую аудиторию. Вместе с тем количество общероссийских газет и журналов на так велико (по сравнению с региональными изданиями), а штат работающих в них журналистов ограничен. Включение в корпус региональной прессы отчасти нивелирует искажения, привносимые указанными факторами. Немаловажно и то, что при таком подходе с большим правом можно говорить о метафорике российской (в плане охвата регионов и количества изданий) прессы.

В отобранных для анализа текстах с помощью выборки фиксировались метафоры из сферы-источника «Болезнь». В ходе обработки материала отсеивалось незначительное количество метафор, несущих мелиоративные смыслы (напр. избавление от недуга, исиеление, выздоровление, идти на поправку, залечивание ран и т.п.). Полученные для каждого года показатели пейоративных метафор болезни сопоставлялись между собой.

\section{Результаты исследования}

Распределение метафорических контекстов по хронологическим сегментам, равным периоду в один год, позволило выделить статистические тенденции в динамике образов болезни. Полученные данные представлены на рис. 1. 


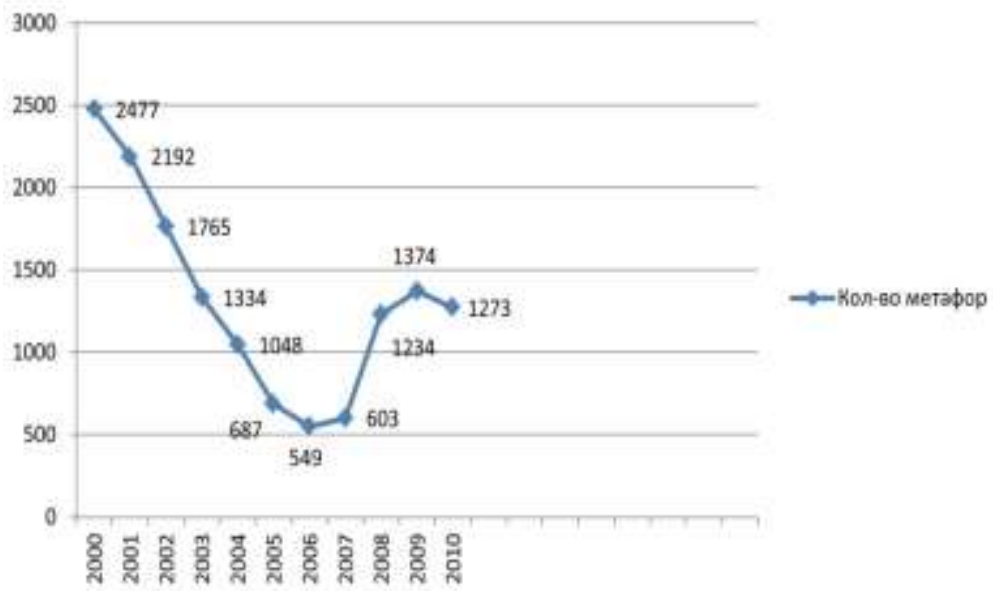

Рис. 1. Распределение метафор болезни по годам публикации в российской прессе.

Как показывают результаты анализа, уровень метафорики болезни снижался в период с 2000 г. (2477 единиц) до 2006 г. (549 единиц). В 2007 г. отмечается незначительный рост метафор болезни, который резко усиливается в 2008-2009 гг. В 2010 г. снова отмечается некоторое снижение уровня метафор болезни. Таким образом, можно выделить три этапа в динамике метафор болезни в рассматриваемый период. Первый этап - планомерное снижение частотности (2000-2006), второй - значительный рост количества метафор болезни (2007-2009 гг.), третий - прекращение роста, стабилизация частотности (2010 г.).

Если принимать во внимание пейоративный характер семантики метафор болезни, то можно отметить корреляцию этих данных с представлениями граждан России об улучшении социально-экономической ситуации, наблюдаемой в годы президентства В. В. Путина. Если в 90-е гг. метафорическая модель «Современная Россия - больной организм» относилась к доминантным метафорическим моделям (Chudinov, 2001), то в 2000-2006 гг. наблюдается стабильное снижение пейоративных смыслов, привносимых образами болезни. Каждый этап в жизни общества связан с определенной конфигурацией концептуальных метафор. Начало XXI в. стало временем метафорического «затишья», совпавшего с периодом экономической и политической стабильности в России.

Однако ситуация меняется во второй период. В 2007 г. начинается рост частотности метафор болезни, что, вероятно, связано с предвосхищением мирового экономического кризиса. В 2007 г. начался финансовый кризис в США, индуцированный ипотечным кризисом в США, банкротством банков и падением цен на фондовом рынке. В российской прессе все чаще раздаются «тревожные звонки», предупреждающие об экономических трудностях, которые могут быть инициированы финансовым кризисом, но удаленность происходящих событий обусловливало слабые проявления кризисного мышления в российском массовом сознании. Тенденция снижения частотности 
меняется ростом частотности, но изменения еще характеризуются низкой амплитудой колебаний.

В 2008 г. разразился мировой экономическим кризис, затронув и российскую экономику. Российский экономический кризис сопровождался снижением, а затем и резким обвалом котировок на фондовом рынке, что сочеталось с резким оттоком капитала и кризисом ликвидности, ужесточением условий заимствований и ухудшением условий внешней торговли. Эти факторы сопровождалось резким ростом частности метафор болезни в российской прессе (с 603 до 1234 метафор, то есть более чем в два раза). В этот период кризисное мироощущение в общественном сознании отразилось в метафорической картине мира, а значимым индикатором этой корреляции послужили пейоративные метафоры болезни. Некоторое снижение частотности метафор болезни в 2010 г. коррелирует с адаптацией к экономическим шокам и стабилизацией экономической ситуации. На этом этапе стало понятно, что потери экономики России оказались меньше, чем это прогнозировалось прежде. Стабилизация экономической ситуации в России, связанная с масштабными антикризисными мерами правительства В. В. Путина и прохождением острой фазы общемирового кризиса, нашла отражение в показателях пейоративной метафоричности медиадикурса.

\section{Выводы}

Применение контент-анализа с учетом экстралингвистических (дискурсивных) факторов на широком текстовом материале показывает, что уровень метафорики болезни тесно коррелирует с текущей экономической и политической ситуацией в современной России. В период социальноэкономической стабильности и роста уровня жизни граждан, в российской прессе наблюдалось последовательное снижение метафор болезни, описывающих окружающую реальность в понятиях, привносящих негативные смыслы. Ухудшение экономической ситуации в мире, напрямую не затронувшее жизнь большинства россиян, отразилось в прекращении снижения частотности и даже незначительном росте образов болезни. Острая фаза мирового экономического кризиса, затронувшая российскую экономику, сопровождалась резким ростом морбиальной метафорики в российской прессе.

Эти результаты позволяют говорить о значимых методологических перспективах комбинированного подхода для дальнейшего изучения сложного взаимодействия между языковыми метафорами в СМИ, концептуальными метафорами в общественном сознании и экстралингвистической действительностью.

Статья подготовлена при финансовой поддержке Российского научного фонда (проект 16-18-02102).

This article is published with the support of Russian Science Foundation (Project number 16-18-02102).

\section{Bibliographic references}

BARANOV, A. N. 2014. Deskriptornaya teoriya metafory. Moscow: Yazyki slavyanskoj kultury. ISBN 978-5-9905856-7-6.

BEVITORI, C. 2015. Discursive Constructions of the Environment in Presidential Speeches 1960-2013: A Diachronic Corpus-Assisted Study. In: Corpora and Discourse Studies. Integrating Discourse and Corpora. Basingstoke: Palgrave Macmillan, 
pp. 110-133. ISBN 978-1-137-43172-1.

CLARK, C. 2008. Chi e il nemico? La rappresentazione delle parti in conflitto in Iraq, 2003. In: Conflitti: Strategie di Rappresentazione della Guerra nell'Era Postmoderna. Rome: Meltemi, pp. 163-168. ISBN 978-8883536540.

CHUDINOV, A. P. 2001. Rossiya v metaforicheskom zerkale: kognitivnoe issledovanie politicheskoj metafory (1991-2000). Ekaterinburg: UrGPU. ISBN 57186-0277-8.

DE LANDTSHEER, C. 1991. Function and the Language of Politics. A Linguistics Uses and Gratification Approach. In: Communication and Cognition, vol. 24, n. 3/4, pp. 299-342. ISSN 0378-0880.

DE LEONARDIS, F. 2008. War as a Medicine: The Medical Metaphor in Contemporary Italian Political Language. In: Social Semiotics, vol. 18, n. 1, pp. 33-45. ISSN 1035-0330.

ELWOOD, W. N. 1995. Declaring War on the Home Front: Metaphor, Presidents, and the War on Drugs. In: Metaphor and Symbol, vol. 10, n. 2, pp. 93-114. ISSN 1532-7868.

FELBERG, T. R. 2007. Inhabiting the Theater of War: The Discourse Models of the NATO bombing of Yugoslavia in Milosevic's address to the nation and Đukanović's address to the citizens of Montenegro. In: Critical Approaches to Discourse Analysis Across Disciplines, vol. 1(1), pp. 124-147. ISSN 1752-3079.

KELLY-HOLMES, H. - O'REGAN, V. 2004. "The spoilt children of Europe". German press coverage of the Nice Treaty referenda in Ireland. In: Journal of Language and Politics, vol. 3, n. 1, pp. 81-116. ISSN 1569-2159.

LOMBARDO, L. 2007. The linguistic construction of 'objectivity' in TV news: a corpus-assisted discourse studies approach. In: Lingue e linguaggi specialistici: studi in onore di Leo Schena. Rome: CISU, pp. 171-191. ISBN 978-88-7975-402-5.

MILLIKEN, J. L. 1996. Metaphors of Prestige and Reputation in American Foreign Policy and American Realism. In: Post-Realism: The Rhetorical Turn in International Relation. East Lancing: Michigan State University Press, pp. 217-238. ISBN 9780870134616.

MORENO LARA, M. A. 2004. La metafora conceptual y el lengua político periodístico: configuración, interacciones y niveles de descripción. Logrono: Universidad de la Rioja. ISBN 84-689-1174-7.

MURPHY, A. C. 2009. Editorials and Opinion Articles in the CorDis corpus: a transversal study. In: Corpus-assisted discourse studies on the Iraq conflict: Wording the war. London: Routledge, pp. 186-207. ISBN 9780415871372.

MUSOLFF, A. 2004. Metaphor and Political Discourse. Analogical Reasoning in Debates about Europe. Basingstoke: Palgrave MacMillan. ISBN 978-1-4039-3389-8.

MUSOLFF, A. 2006. Politicheskaya terapija posredstvom genotsida: antisemitskie konceptualnye lozungi v knige Gitlera "Majn Kampf". In: Zarubezhnaya politicheskaya lingvistika. Moscow: Flinta-Nauka, pp. 202-230.

MUSOLFF, A. 2016. Political Metaphor Analysis. Discourse and Scenarios. London: Bloomsbury Academic. ISBN 9781441160669.

NASALSKI I. 2004. Die politische Metapher im Arabischen. Untersuchungen zu Semiotik und Symbolik der politischen Sprache am Beispiel Ägyptens. Wiesbaden: Harrasowitz. ISBN 978-3-447-05004-3.

OBERHUBER, F. - BÄRENREUTER, C. - KRZYZANOWSKI, M., SCHÖNBAUER, H., WODAK, R. 2005. Debating the European Constitution: On representations of Europe/the EU in the press. In: Journal of Language and Politics, vol. 4, n. 2, pp. 227-271. ISSN 1569-2159. 
PARTINGTON, A. 2010. Modern Diachronic Corpus-Assisted Discourse Studies (MD-CADS) on UK newspapers: an overview of the project. In: Corpora, vol. 5(2), pp. 83-108. ISSN 1749-5032.

RICCIO, G. 2009. White House press briefings as a message to the world. In: Corpusassisted discourse studies on the Iraq conflict: Wording the war. London: Routledge, pp. 108-140. ISBN 9780415871372.

VERTESSEN, D. - DE LANDTSHEER, Ch. 2008. A Metaphorical Election Style: Use of Metaphor at Election Time. In: Political Language and Metaphor: Interpreting and Changing the World. London: Routledge, pp. 271-285. ISBN 978-0415663762. VESSEY, R. 2016. Language ideologies in social media. The case of Pastagate. In: Journal of Language and Politics, vol. 15 , n. 1, pp. 1-24. ISSN 1569-2159.

ZBIERSKA-SAWALA, A. 2004. The Conceptualisation of the European Union in Polish Public Discourse, 2002-2003. In: Journal of Multilingual and Multicultural Development, vol. 25, n. 5/6, pp. 408-423. ISSN0143-4632.

Words: 2610

Characters: 21249 (11, 80 standard pages)

Prof. Eduard V. Budaev, Doctor

Nizhny Tagil State Social Pedagogical Institute

Branch of Russian State Vocational Pedagogical University

57, Krasnogvardeyskaya St.

620031 Nizhny Tagil

Russia

aedw@mail.ru 